Nevşehir Bilim ve Teknoloji Dergisi Cilt 6(1) 30-38 2017

DOI: 10.17100/nevbiltek.288641

URL: http://dx.doi.org/10.17100/nevbiltek.288641

\title{
Emaye Kaplama Endüstrisi Atıksularının Klasik Ve Modifiye Fenton Prosesleri İle
}

Aritımı

\author{
Serkan ŞAHINKAYA* \\ Nevşehir Hacı Bektaş Veli Üniversitesi, Mühendislik Mimarlık Fakültesi, Çevre Mühendisliği Bölümü,
}

Nevşehir

Öz

Emaye kaplama endüstrisi atıksuları yağ-gres, renk, kimyasal oksijen ihtiyacı (KOI), siyanür ve krom, nikel, çinko, kadmiyum, demir vb. ağır metal içeriği yüksek atıksulardır. Bu çalışma kapsamında, emaye kaplama endüstrisi atıksularının klasik ve mofidiye Fenton prosesleri ile arıtımı incelenmiştir. Her iki metodun da verimini izlemek için hedef parametre olarak kimyasal oksijen ihtiyacı (KOİ) seçilmiştir. Çalışmada, atıksuyun başlangıç $\mathrm{pH}$ 'ı, katalist demir $\left(\mathrm{Fe}^{2+}\right.$ veya $\left.\mathrm{Fe}^{0}\right)$ konsantrasyonu ve hidrojen peroksit $\left(\mathrm{H}_{2} \mathrm{O}_{2}\right)$ konsantrasyonlarının optimizasyonu gerçekleştirilmiştir. Ayrıca optimum şartlarda kinetik çalışma da gerçekleştirilmiştir. Optimum deneysel şartlar, klasik Fenton prosesi için $\mathrm{pH}=3$, $\left[\mathrm{Fe}^{2+}\right]=150 \mathrm{mg} / \mathrm{L}$ ve $\left[\mathrm{H}_{2} \mathrm{O}_{2}\right]=250 \mathrm{mg} / \mathrm{L}$ ve modifiye Fenton prosesi için $\mathrm{pH}=3,\left[\mathrm{Fe}^{0}\right]=200 \mathrm{mg} / \mathrm{L}$ ve $\left[\mathrm{H}_{2} \mathrm{O}_{2}\right]=200 \mathrm{mg} / \mathrm{L}$ olarak belirlenmiştir. Optimum şartlarda, klasik Fenton prosesi ile KOI gideriminin ilk 5 dakikada reaksiyon bileşenlerinin ortamdaki yeterli varlığından dolayı çok hızlı gerçekleștiği ve sonrasında giderim hızının azaldığı gözlemlenmiştir. Modifiye Fenton prosesinde ise KOİ giderimi, metalik demir tozunun öncelikle çözünmesi gerektiği için daha yavaş gerçekleşmiştir. Kinetik çalışmada ise Fenton prosesinin her iki uygulamasının da ikinci derece kinetiğe uyduğu belirlenmiştir.

Anahtar Kelimeler: Atıksu, emaye kaplama, Fenton, KOİ.

\section{Treatment Of Enamel Coating Facility Wastewaters Via Conventional and Modified Fenton Processes}

\begin{abstract}
Enamel coating facility wastewaters include high concentrations of oil-grease, colour, chemical oxygen demand (COD) and heavy metals such as chromium, nickel, cadmium, iron and zinc. In this study, treatment of enamel coating facility wastewaters by conventional and modified Fenton process was investigated. The COD parameter was selected as the target parameter in the wastewater for both Fenton processes. The optimization of initial $\mathrm{pH}$, catalyst iron concentration and hydrogen peroxide $\left(\mathrm{H}_{2} \mathrm{O}_{2}\right)$ concentration was performed for an efficient treatment. Also change in COD concentration as a function of time under optimal conditions and kinetic studies were investigated. As a result of the study, optimum experimental conditions were determined as $\mathrm{pH}$ $=3,\left[\mathrm{Fe}^{2+}\right]=150 \mathrm{mg} / \mathrm{L}$ and $\left[\mathrm{H}_{2} \mathrm{O}_{2}\right]=250 \mathrm{mg} / \mathrm{L}$ for conventional Fenton process and $\mathrm{pH}=3,\left[\mathrm{Fe}^{0}\right]=200 \mathrm{mg} / \mathrm{L}$ ve $\left[\mathrm{H}_{2} \mathrm{O}_{2}\right]=200$ $\mathrm{mg} / \mathrm{L}$ for modified Fenton process. Under these conditions, due to the abundant presence of reaction components in the reaction mixture, COD removal was occurred rapidly in the first 5 minutes of reaction period, and later on the removal rate and efficiency were decreased in the remained period because of the decreases in the Fenton reagents. COD removal via modified Fenton process was slower compared to the conventional Fenton process, since metallic iron had to solubilize first in the modified process. Consequently, it was determined that conventional Fenton process is an efficient process for the treatment of enamel coating facility wastewaters. The experimental data was fitted to second order kinetics for both Fenton processes.
\end{abstract}

Keywords: Enamel coating, COD, Fenton, wastewater.

*e-mail: serkansahinkaya@gmail.com 


\section{Giriş}

Emaye kaplama endüstrisi atıksuları yağ-gres, renk, kimyasal oksijen ihtiyacı (KOİ) ve krom, nikel, çinko, kadmiyum, demir vb. ağır metal içeriği yüksek atıksulardır [1]. Atıksuyun içerdiği kadmiyum, krom gibi ağır metaller, toksik ve kanserojen özelliktedir. Uygun arıtım yapılmaksızın alıcı su ortamlarına deşarj edilmesi halinde sucul canlıların ölümüne, su kalitesinin düşmesine ve içme, kullanma ve sulama suyu olarak kullanılamaz hale gelmesine neden olmaktadır. Bu nedenle, emaye kaplama endüstrisi atıksularının uygun ve yeterli bir arıtmadan sonra deşarj edilmesi gerekmektedir. Bu amaçla genellikle kimyasal veya fizikokimyasal arıtma tercih edilmektedir. Bu çalışmada ise, emaye kaplama atıksularının ileri oksidasyon prosesi olan Fenton prosesinin iki farklı uygulaması ile arıtımı araştırılmıştır.

Klasik Fenton prosesi kuvvetli asidik şartlarda hidrojen peroksidin $\left(\mathrm{H}_{2} \mathrm{O}_{2}\right)$ ferro demir $\left(\mathrm{Fe}^{2+}\right)$ ile reaksiyona girerek katalitik olarak parçalanmasına dayanmaktadır (1) [2]. Bu reaksiyon sonucunda bilinen en güçlü ikinci oksidant radikal olan hidroksil $\left(\mathrm{OH}^{\bullet}\right)$ üretilmektedir. $\mathrm{OH}^{\bullet}$, organik ve inorganik kökenli yapıları oksitleyebilen seçici olmayan bir radikaldir (2) [3]. Uygulanması basit, ileri teknoloji ve kalifiye personel gerektirmeyen Fenton prosesi, bir ileri oksidasyon prosesidir. Bu fizikokimyasal aritma metodu, özellikle kesikli üretimin yapıldığı endüstriyel atıksuların arıtımında kullanılabilen, hem organik ve inorganik kirleticiler için oksidasyon hem de askıda ve koloidal kirleticiler için koagülasyon flokülasyon - çöktürme mekanizmalarını içeren etkili bir fizikokimyasal arıtma prosesidir [2]. Bu özellikleri ile Fenton prosesi, emaye kaplama endüstrisi atıksularının arıtımı için idealdir. Fenton prosesi dört aşamada yürütülmektedir. Bunlar, pH ayarlaması, reaksiyon aşaması, nötralizasyon ve çöktürmedir. pH ayarlaması aşamasında, atıksu pH'ı, reaksiyonun gerçekleşebileceği asidik pH'a ayarlanmaktadır. Reaksiyon aşamasında, Fenton reaktifleri olan katalizör demir ve hidrojen peroksit $\left(\mathrm{H}_{2} \mathrm{O}_{2}\right)$ sırasıyla ilave edilmektedir. Her iki kimyasalın ilavesinden sonra, Eşitlik 1'e uygun olarak reaksiyon hızla gerçekleşmektedir. Nötralizasyon aşamasında, reaksiyon periyodu tamamlandıktan sonra, çözünmüş formdaki demirin çöktürülmesi için pH 7 - 8 civarına ayarlanmaktadır. Çöktürme aşamasında ise, oluşan demir hidroksit floklarının çöktürülmesi için atıksu, durgun şartlarda yarım saat kadar bekletilmekte ve Fenton süreci böylece sonlandırılmaktadır.

$$
\begin{array}{ll}
\mathrm{Fe}^{2+}+\mathrm{H}_{2} \mathrm{O}_{2} \rightarrow \mathrm{Fe}^{3+}+\mathrm{OH}^{\bullet}+\mathrm{OH}^{-} & \mathrm{k}_{1}=70 \mathrm{M}^{-1} \mathrm{~s}^{-1} \\
\mathrm{RH}+\mathrm{OH}^{\bullet} \rightarrow \mathrm{H}_{2} \mathrm{O}+\mathrm{R}^{\bullet} & \mathrm{k}_{2}=10^{9}-10^{10} \mathrm{M}^{-1} \mathrm{~s}^{-1}
\end{array}
$$

Fenton prosesinde Eşitlik 1'e uygun olarak, oksidasyon reaksiyonu çok hızlı gerçekleşmektedir. Ancak reaksiyon ortamında bulunan ferro demir $\left(\mathrm{Fe}^{2+}\right)$ ve hidrojen peroksidin zamanla azalması sonucunda; $\mathrm{OH}^{\bullet}$ üretimi ve böylece reaksiyon hızı da azalmaktadır.

Fenton prosesinde, katalizör demir olarak metalik demir tozu $\left(\mathrm{Fe}^{0}\right)$ da kullanılabilmekte ve buna “modifiye Fenton prosesi” denilmektedir [4, 5]. Modifiye Fenton prosesinde, katalist demir çözünmemiş formda (metalik toz halinde) sisteme verildiği için, öncelikle asidik şartlarda demirin çözünmesi gerekmektedir. $\mathrm{Fe}^{0}{ }^{\prime}$ ’n sudaki çözünürlüğü pH'a bağlı olarak zamanla gerçekleşmektedir (3) [6]. Bu durum süreç verimini sınırlamaktadır. Ancak hurda metalik demirin de süreçte kullanılabilirliğine imkân tanıdığı için, süreç maliyetinin azalmasına neden olabilmektedir. Ayrıca, Eşitlik 4’te de gösterildiği gibi, 
ferrik demirin, ferro demire indirgenmesi de gerçekleşebilmekte ve böylece süreç veriminin artmasına katk1 sağlamaktadır [6].

$$
\begin{aligned}
& \mathrm{Fe}^{0}+2 \mathrm{H}^{+} \rightarrow \mathrm{Fe}^{2+}+\mathrm{H}_{2} \\
& 2 \mathrm{Fe}^{3+}+\mathrm{Fe}^{0} \rightarrow 3 \mathrm{Fe}^{2+}
\end{aligned}
$$

Eşitlik 3'e uygun olarak, modifiye Fenton prosesinde metalik demir, asidik reaksiyon ortamında çözündükten ve $\mathrm{Fe}^{2+}$ halinde ortamda var olduktan sonra Eşitlik 1'de gösterildiği gibi Fenton reaksiyonu gerçekleşmektedir.

$\mathrm{Bu}$ çalışmada, emaye kaplama atıksularının klasik ve modifiye Fenton prosesleri ile arıtımı araştırılmıştır. Her iki proses için de arıtma verimine etki eden atıksuyun başlangıç pH'ı, katalist demir dozları $\left(\mathrm{Fe}^{2+}\right.$ veya $\left.\mathrm{Fe}^{0}\right)$ ve $\mathrm{H}_{2} \mathrm{O}_{2}$ dozlarının etkileri incelenmiştir. Çalışma kapsamında hedef parametre olarak kimyasal oksijen ihtiyacı (KOI) seçilmiş ve proses optimizasyonları ve kinetik çalışma, KOİ parametresi esas alınarak gerçekleştirilmiştir.

\section{Materyal ve Metot}

\subsection{Endüstriyel Atıksu ve Kimyasallar}

Çalışmada kullanılan atıksu, bir metal kaplama tesisinden alınmıştır. Atıksu herhangi bir ön işlemden geçirilmeden doğrudan kullanılmıştır. Kullanılan atıksuyun bazı önemli parametreleri Tablo 1 'de sunulmuştur.

Tablo 1. Atıksu karakteristiği.

\begin{tabular}{lc}
\multicolumn{2}{c}{ Tablo 1. Atıksu karakteristiği. } \\
\hline Parametre & Değer \\
pH & 7,1 \\
Kimyasal oksijen ihtiyacı (KOI) & $590 \mathrm{mg} / \mathrm{L}$ \\
Askıda katı madde (AKM) & $410 \mathrm{mg} / \mathrm{L}$ \\
Yağ - gres & $23 \mathrm{mg} / \mathrm{L}$ \\
Demir & $5,10 \mathrm{mg} / \mathrm{L}$ \\
Krom (Krom $\left.{ }^{6+}\right)$ & $2,60 \mathrm{mg} / \mathrm{L}$ \\
Nikel & $0,05 \mathrm{mg} / \mathrm{L}$ \\
Çinko & $0,35 \mathrm{mg} / \mathrm{L}$ \\
Kadmiyum & $0,07 \mathrm{mg} / \mathrm{L}$ \\
Klorür $\left(\mathrm{Cl}^{-}\right)$ & $3,6 \mathrm{mg} / \mathrm{L}$ \\
\hline
\end{tabular}

Çalışmada kullanılan kimyasallar Merck (Almanya) firmasından temin edilmişlerdir ve analitik saflık derecesindedirler. Deneysel çözeltilerin hazırlanmasında ise ultra saf su kullanılmıştır.

\subsection{Deneysel Prosedür}

Klasik Fenton prosesi deneyleri, jar testi cihazında (MTops) $500 \mathrm{~mL}$ hacminde atıksu kullanılarak gerçekleştirilmiştir. Atıksuların başlangıç pH'larının asidik şartlara ayarlanması için 0,1 ve 1 $\mathrm{N} \mathrm{H}_{2} \mathrm{SO}_{4}$ çözeltileri kullanılmıştır. $\mathrm{pH}$ 'ın istenen değere ayarlanmasından sonra, istenen dozlarda sırasıyla ( $\mathrm{FeSO}_{4} .7 \mathrm{H}_{2} \mathrm{O}$ olarak) $\mathrm{Fe}^{2+}$ ve $\mathrm{H}_{2} \mathrm{O}_{2}$ dozlaması gerçekleştirilmiştir. Hidrojen peroksidin dozlanmasından 
sonra, 1 saatlik reaksiyon süresinin başladığı kabul edilmiştir. Reaksiyon süresi boyunca, reaksiyon ortamı 90 rpm'lik sabit hızda karıştırılmıştır. Bu sürenin sonunda, ortam pH'ı 0,1 ve 1 N'lik $\mathrm{NaOH}$ çözeltileri kullanılarak 7,5'a ayarlanmış ve karıştırma durdurularak oluşan demir hidroksit floklarının çökelmesi için 30 dakika süre ile durgun şartlarda bekletilmiştir.

Modifiye Fenton prosesi deneyleri, jar testi cihazında klasik Fenton prosesinde izlenen prosedürde gerçekleştirilmiş̧ir. Farklı olarak ferro demir yerine, metalik demir tozu kullanılmıştır.

Fenton prosesinin her iki farklı uygulamasında da çöktürme işleminden sonra, üst duru fazdan pipetle numuneler alınmıştır. Numuneler, içerisinde mangan oksit $\left(\mathrm{MnO}_{2}\right)$ bulunan beherlerde birkaç dakika bekletilmiştir. $\mathrm{MnO}_{2}$, kalıntı hidrojen peroksidin parçalanarak KOİ sonuçlarına pozitif girişim yapmasını önlemek amacıyla kullanılmıştır [7-9]. KOİ ölçümlerinden önce numuneler çökmemiş demir hidroksit $\left(\mathrm{Fe}(\mathrm{OH})_{3}\right)$ floklarının giderilmesi için $0,45 \mu \mathrm{m}$ gözenek çaplı membran filtre kâğıtlarından süzülmüş ve KOİ analizlerinde bu süzüntüler kullanılmıştır. Analizler, Standart Metotlar’a uygun olarak yapılmıştır [10].

\section{Bulgular ve Tartış̧ma \\ 3.1. $\quad$ pH'In Etkisi}

Fenton reaksiyonu kuvvetli asit şartlarda gerçekleştiği için, ortam pH'ı optimize edilmesi gereken en önemli parametredir. Çünkü $\mathrm{pH}$, katalizör vazifesi gören demirin türünü değiştirerek reaksiyon verimine doğrudan etki etmekte ve oksitleyici $\mathrm{OH}^{*}$ radikalinin üretilen miktarına da tesir etmektedir [11]. $\mathrm{Bu}$ nedenle, çalışma kapsamında öncelikle atıksuyun başlangıç pH'ının, Fenton prosesinin her iki farklı uygulamasının KOİ giderimi üzerine etkisi incelenmiştir. Her iki proses için de pH'ın etkisi, pH $2-7$ aralığında $100 \mathrm{mg} / \mathrm{L}$ katalist demir ve $200 \mathrm{mg} / \mathrm{L} \mathrm{H}_{2} \mathrm{O}_{2}$ konsantrasyonlarında KOİ giderim verimine bağlı olarak araştırılmış ve deneysel sonuçlar Şekil 1'de verilmiştir.

Şekil 1'de gösterildiği gibi, klasik Fenton prosesinde reaksiyon ortamının başlangıç pH'ının 3’ten 2'ye düşürülmesi ile KOİ giderim verimi \% 47'den \% 32'ye düşmüştür. Asidik şartların gerekli olduğu Fenton prosesinin arıtma verimindeki bu düşüşün başlıca nedenleri, kuvvetli asidik şartlarda $\mathrm{H}^{+}$ iyonunun $\mathrm{OH}^{\bullet}$ radikallerini süpürmesi, $\mathrm{H}^{+}$iyonunun $\mathrm{H}_{2} \mathrm{O}_{2}$ ile reaksiyona girerek daha stabil bir yapı olan $\mathrm{H}_{3} \mathrm{O}_{2}{ }^{+}$a dönüştürmesi ve $\mathrm{pH}<3$ 'de ferro demirin $\mathrm{Fe}(\mathrm{OH})^{2+}$ olarak hidrojen peroksit ile daha yavaş reaksiyona giren yapıya dönüştürülmesidir [3]. Modifiye Fenton prosesinde ise, Eşitlik 1'e uygun olarak, pH 2'de \% 45'lik KOİ giderimi sağlanırken; pH'ın 3'e yükselmesi ile metalik demirin çözünürlüğünü azalttığı için KOİ giderimi de \% 41,5'e düşmüştür. Her iki proseste de pH'ın 3'ün üstüne yükselmesi, reaksiyon ortamında ferro demirin ferrik hidroksil bileşiklerine dönüştürülmesi sonucunda, KOİ giderim verimi sürekli azalmıştır [12]. Bu deneysel çalışmanın sonucunda optimum başlangıç pH'ı, hem klasik hem de modifiye Fenton prosesleri için pH 3 olarak belirlenmiştir. Modifiye Fenton prosesinde maksimum verimin elde edildiği pH 2 ile pH 3 arasında kayda değer bir fark olmadığ 1 için, daha az kimyasal sarfiyatı gerektirecek olan pH 3 optimum değer olarak seçilmiştir. pH optimizasyonu aşamasında bulunan bu sonuçlar, Fenton prosesi üzerine yapılmış literatürdeki çalışmalar ile benzerdir [12]. 


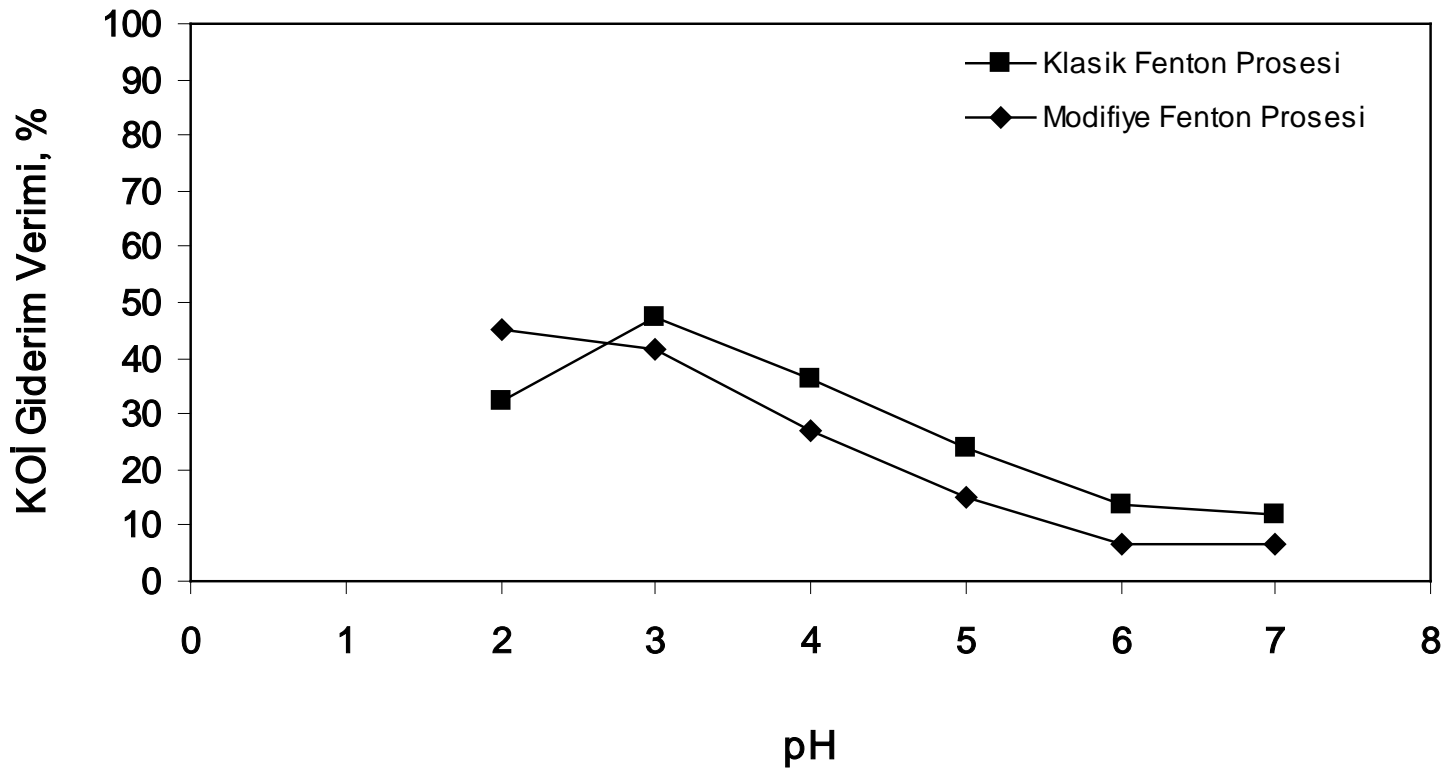

Şekil 1. Başlangıç pH'ının KOİ giderimine etkisi.

\subsection{Demir Dozunun Etkisi}

Fenton prosesinde optimize edilmesi gereken bir diğer önemli parametre, reaksiyonda katalizör vazifesi gören demirin dozudur [13]. Demir miktarının az olması, Eşitlik 1'de sunulan reaksiyon denklemine göre, üretilen $\mathrm{OH}^{\bullet}$ radikalinin miktarını azaltarak oksidasyon veriminin düşmesine neden olurken; aşırı miktarda kullanılması ise hem radikal süpürücü etki yaparak reaksiyon veriminin düşmesine hem de tehlikeli atık sınıfına giren kimyasal arıtma çamurunun fazla üretilmesine neden olmaktadır. Bu nedenlerle, uygulanacak demir dozunun optimize edilmesi önemlidir. Klasik ve modifiye Fenton prosesleri için demir dozunun optimizasyonu, pH 3'te $200 \mathrm{mg} / \mathrm{L} \mathrm{H}_{2} \mathrm{O}_{2}$ konsantrasyonunda 50 - $400 \mathrm{mg} / \mathrm{L}$ demir konsantrasyonu aralı̆̆ında incelenmiştir.

Deneysel sonuçlar Şekil 2'de sunulmuştur. Bu grafikten de anlaşlacağı gibi, klasik Fenton prosesinde artan ferro demir miktarı ile Eşitlik 1 ve 2'ye uygun olarak $250 \mathrm{mg} / \mathrm{L} \mathrm{Fe}^{2+}$ konsantrasyonuna kadar KOİ giderim verimi sürekli artmıştır. $250 \mathrm{mg} / \mathrm{L} \mathrm{Fe}^{2+}$ konsantrasyonunda maksimum giderim verimi (\% 71,1) elde edilmiştir. Daha yüksek ferro demir konsantrasyonlarında, Eşitlik 5'te gösterdiği gibi, fazla ferro demir ortamdaki $\mathrm{OH}^{*}$ radikali ile reaksiyona girerek radikal süpürücü etkiye neden olmuş ve böylece KOİ giderim verimini azaltmıştır [13]. Modifiye Fenton prosesinde ise uygulanan $\mathrm{Fe}^{0}$ dozundaki artış ile KOİ giderimi de sürekli artış göstermiştir. Bu artış, $200 \mathrm{mg} / \mathrm{L} \mathrm{Fe}^{0}$ dozuna kadar kayda değer iken, daha yüksek dozlarda ihmal edilebilir seviyelerde olmuştur. Klasik Fenton prosesinde gerçekleşen fazla demirin radikal süpürücü etkisinin modifiye proseste görülmemesinin sebebi ise, metalik demir tozunun $\left(\mathrm{Fe}^{0}\right)$ atıksu içerisinde çözünmesinin zaman alması ve klasik proseste olduğu gibi başlangıç anında ferro demirin bir anda verilmemesidir. Sonuç olarak klasik Fenton prosesinde \% 63'lük giderimin sağlandığ 150 mg/L'lik $\mathrm{Fe}^{2+}$ dozu optimum olarak belirlenirken; modifiye Fenton prosesinde \% 62'lik veririm elde edildiği $200 \mathrm{mg} / \mathrm{L}^{\prime} l i k \mathrm{Fe}^{0}$ dozu optimum olarak tespit edilmiştir.

$$
\mathrm{Fe}^{2+}+\mathrm{OH}^{\bullet} \rightarrow \mathrm{Fe}^{3+}+\mathrm{OH}^{-}
$$




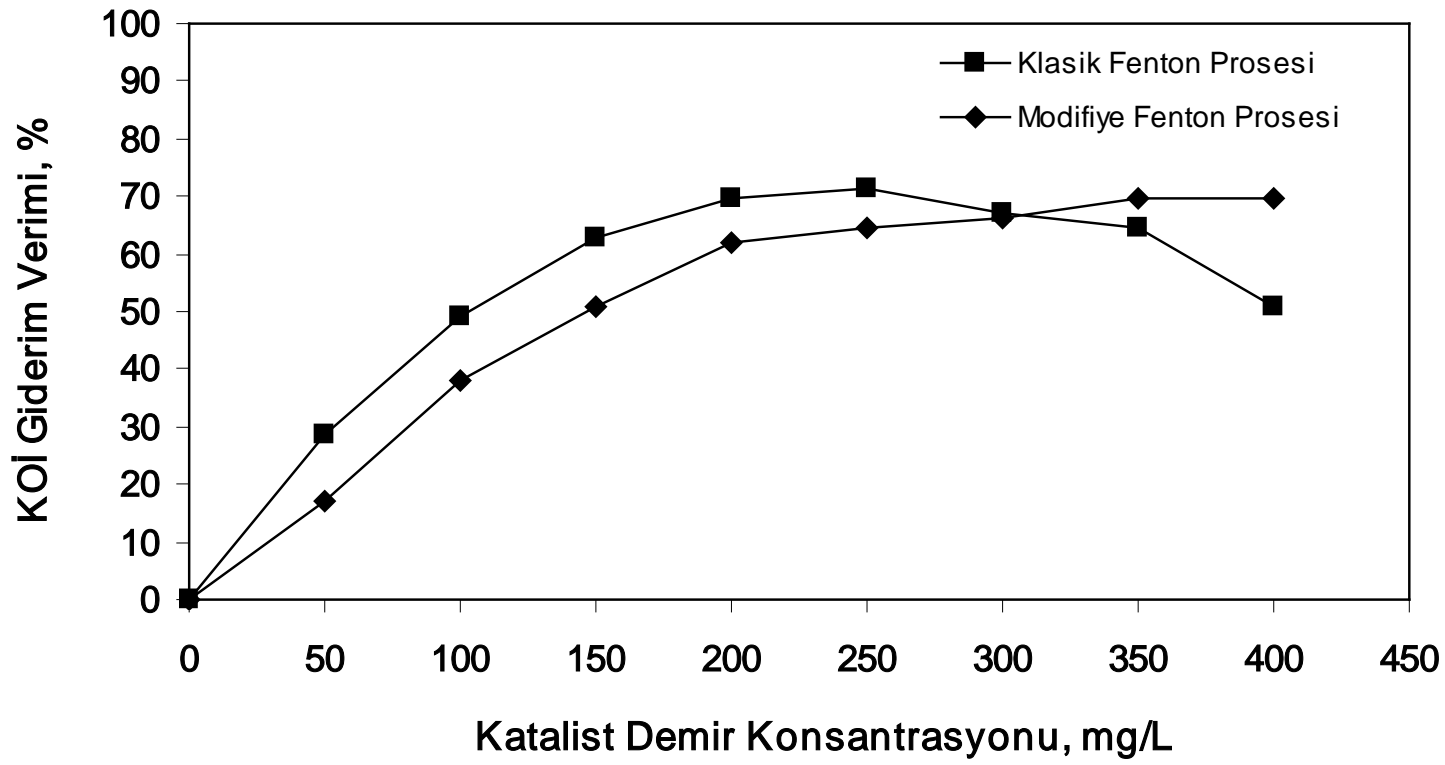

Şekil 2. Katalist demir konsantrasyonunun KOİ giderimine etkisi.

\section{3. $\mathrm{H}_{2} \mathrm{O}_{2}$ Dozunun Etkisi}

Fenton reaksiyonunda üretilen $\mathrm{OH}^{\bullet}$ radikallerinin kaynağı kullanılan hidrojen peroksittir (1) [2]. Ancak aşırı miktarda uygulanması, arıtma maliyetini arttırmaktadır. Ayrıca, hidroksil radikallerinin süpürülmesine neden olarak arıtma veriminin de düşmesine neden olabilmektedir [2, 14]. Bu çalışmada $\mathrm{H}_{2} \mathrm{O}_{2}$ optimizasyonu, optimize edilmiş olan $\mathrm{pH}$ ve demir dozlarında çalışılmıştır.

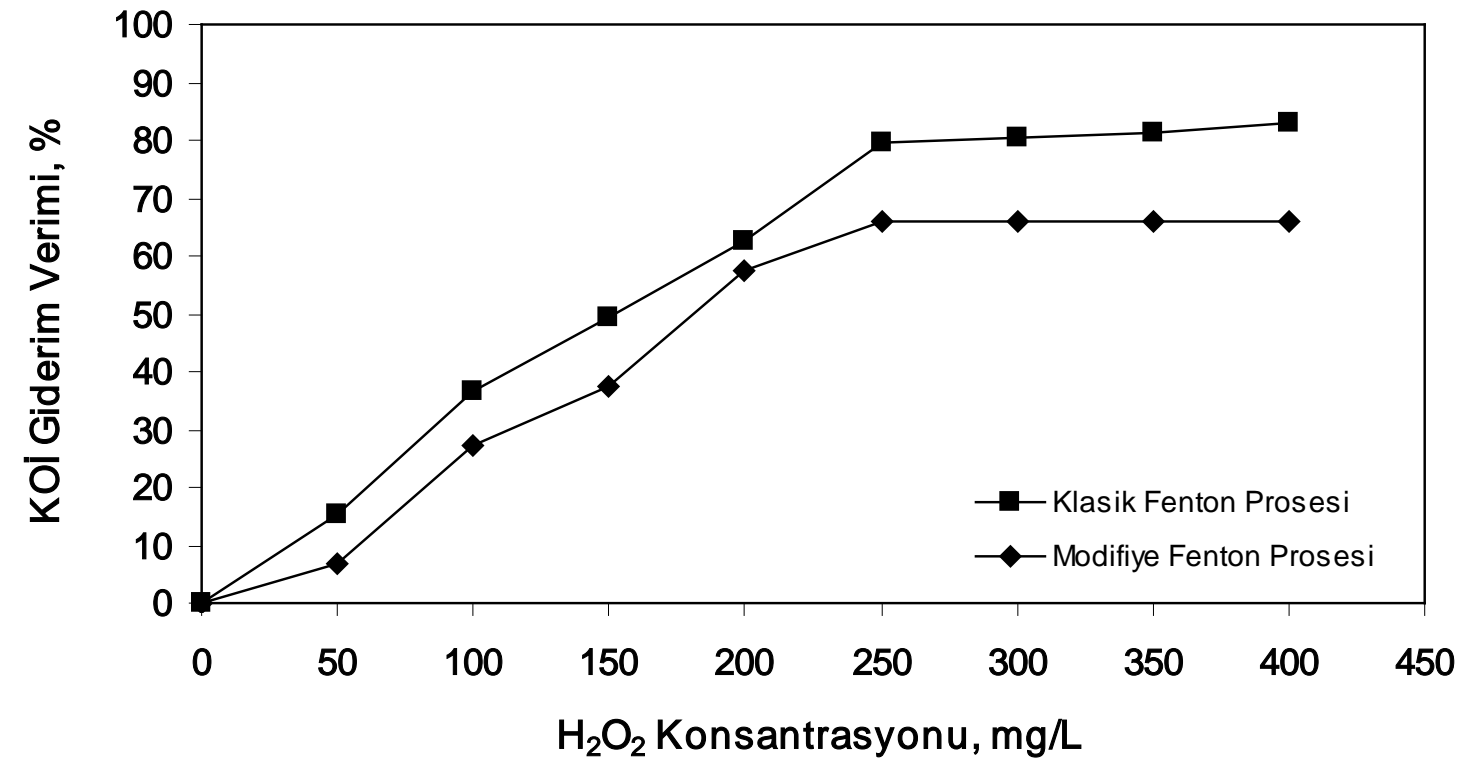

Şekil 3. $\mathrm{H}_{2} \mathrm{O}_{2}$ konsantrasyonunun KOİ giderimine etkisi.

Şekil 3'ten de anlaşılacağ üzere, klasik Fenton prosesinde artan $\mathrm{H}_{2} \mathrm{O}_{2}$ dozu ile Eşitlik 1'e uygun olarak KOİ giderim verimi sürekli yükselmiştir. Ancak bu artış \% 80 KOİ gideriminin elde edildiği 250 mg/L'lik dozdan sonra ihmal edilebilir seviyede kalmıştır. Modifiye Fenton prosesinde ise $200 \mathrm{mg} / \mathrm{L}$ 
$\mathrm{H}_{2} \mathrm{O}_{2}$ dozuna kadar KOİ giderimi (\%58) kayda değer artış gösterirken, uygulanan dozun $250 \mathrm{mg} / \mathrm{L}$ 'ye yükselmesi ile hafif bir artış olmuştur. Daha yüksek dozlarda ise KOİ gideriminde bir artış belirlenemiştir. Böylece, klasik ve modifiye Fenton prosesleri için optimum $\mathrm{H}_{2} \mathrm{O}_{2}$ konsantrasyonları 250 ve $200 \mathrm{mg} / \mathrm{L}$ olarak tespit edilmiştir.

\subsection{Kinetik Çalışma}

Emaye kaplama atıksularından KOİ giderimi için optimum şartlar, klasik Fenton prosesi için pH 3, $\left[\mathrm{Fe}^{2+}\right]=150 \mathrm{mg} / \mathrm{L}$ ve $\left[\mathrm{H}_{2} \mathrm{O}_{2}\right]=250 \mathrm{mg} / \mathrm{L}$ ve modifiye Fenton prosesi için ise $\mathrm{pH} 3,\left[\mathrm{Fe}^{2+}\right]=200 \mathrm{mg} / \mathrm{L}$ ve $\left[\mathrm{H}_{2} \mathrm{O}_{2}\right]=200 \mathrm{mg} / \mathrm{L}$ olarak belirlenmiştir. Bu şartlarda, zamana bağlı olarak KOİ konsantrasyonunun değişimi oda sıcaklığında denenmiş ve sonuçlar da Şekil 4’te gösterilmiştir. Bu şekilde de gösterildiği gibi, ilk 5 dakikada Eşitlik 1'e uygun olarak ortamda katalist ferro demir ile $\mathrm{H}_{2} \mathrm{O}_{2}$ 'in yeterli miktarda bulunduğu için klasik Fenton prosesinde oksidasyon reaksiyonu hızla gerçekleşmiştir. Modifiye Fenton prosesinde ise giderim hızı metalik demirin çözünmesine bağlı olduğu için daha yavaş gerçekleşmiştir. Her iki proseste de reaksiyon bileşenlerinin ortamda zamanla azalması sonucunda, Şekil 4'te de gösterildiği gibi, KOİ giderim hızı da azalmıştır. Böylece emaye kaplama atıksularından klasik Fenton prosesi ile KOİ gideriminin iki aşamada gerçekleştiği ve bunların ilk 5 dakikadaki hızlı oksidasyon aşaması, kalan 55 dakikadaki periyodun ise yavaş oksidasyon aşaması olduğu belirlenmiştir. Modifiye Fenton prosesinde ise, ilk 20 dakikadan demirin çözünmesine bağlı olarak reaksiyonun daha hızlı gerçekleştiği, sonraki 40 dakikalık periyotta ise reaksiyonun yavaşladığı gözlemlenmiştir. Klasik Fenton prosesinde reaksiyonun daha hızlı gerçekleşmesinin sebebi, katalist demirin Fenton reaksiyonu için hazır olarak yani çözünmüş formda verilmiş olmasıdır (Eşitlik 1). Bu sonuç literatürdeki Fenton prosesi üzerine yapılmış çalışmalara benzerdir $[4,15]$.

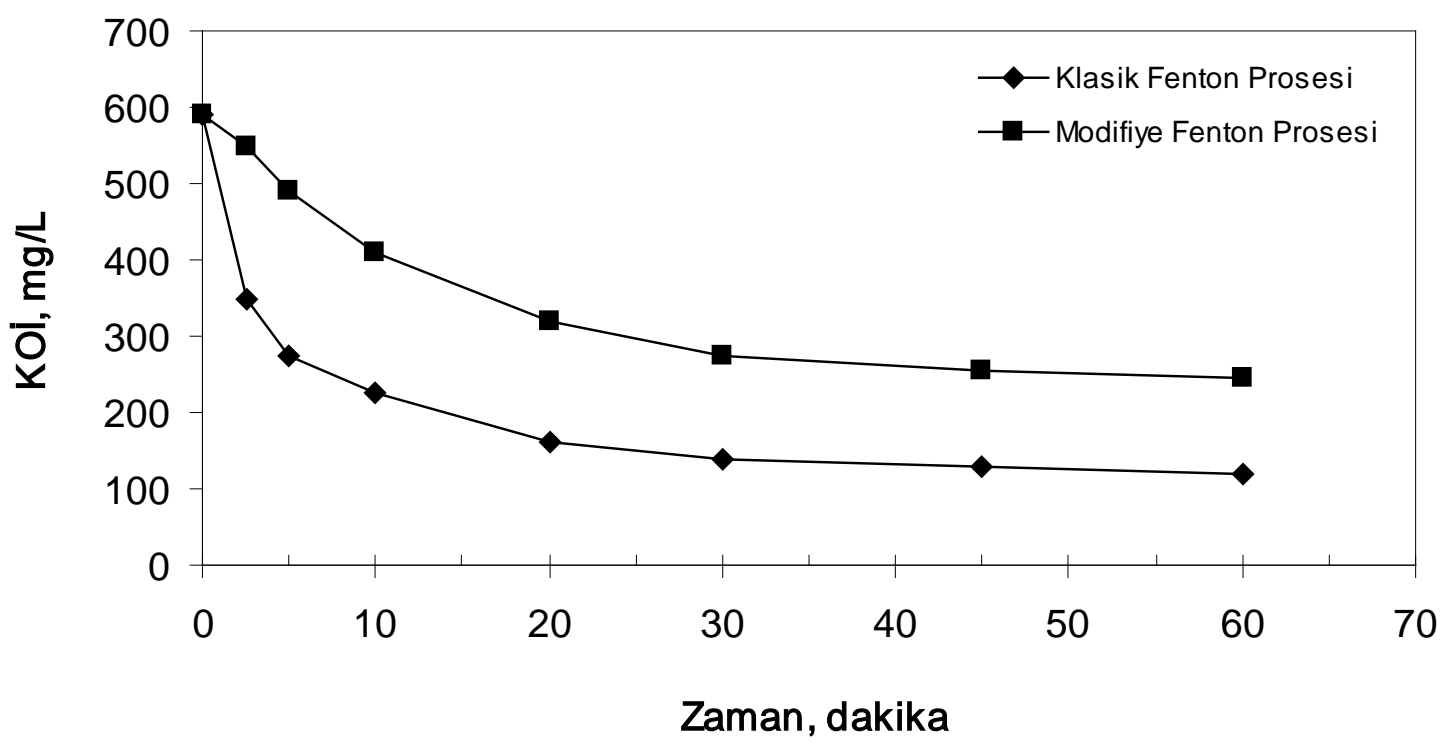

Şekil 4. Zamana bağlı KOİ konsantrasyonunun değişimi. 
Şekil 4'te sunulan zamana bağlı olarak KOİ konsantrasyonlarındaki değişim verilerine, sıfırıncı, birinci ve ikinci derece kinetik modelleri uygulanmıştır. Klasik Fenton prosesi ile emaye kaplama endüstrisi atıksularından KOİ gideriminde sıfırıncı, birinci ve ikinci dereceden kinetik modeller için belirleme katsayıları $\left(\mathrm{R}^{2}\right)$ sırasıyla $0,5420,0,7318$ ve 0,8733 iken, modifiye Fenton prosesi için 0,8769 , 0,9543 ve 0,9946 olarak hesaplanmıştır. Böylece, Şekil 5 'te de gösterildiği gibi, Fenton prosesinin her iki uygulamasının da kirleticilerin konsantrasyonunun fonksiyonu olarak ikinci dereceden kinetiğe uyduğu belirlenmiştir.
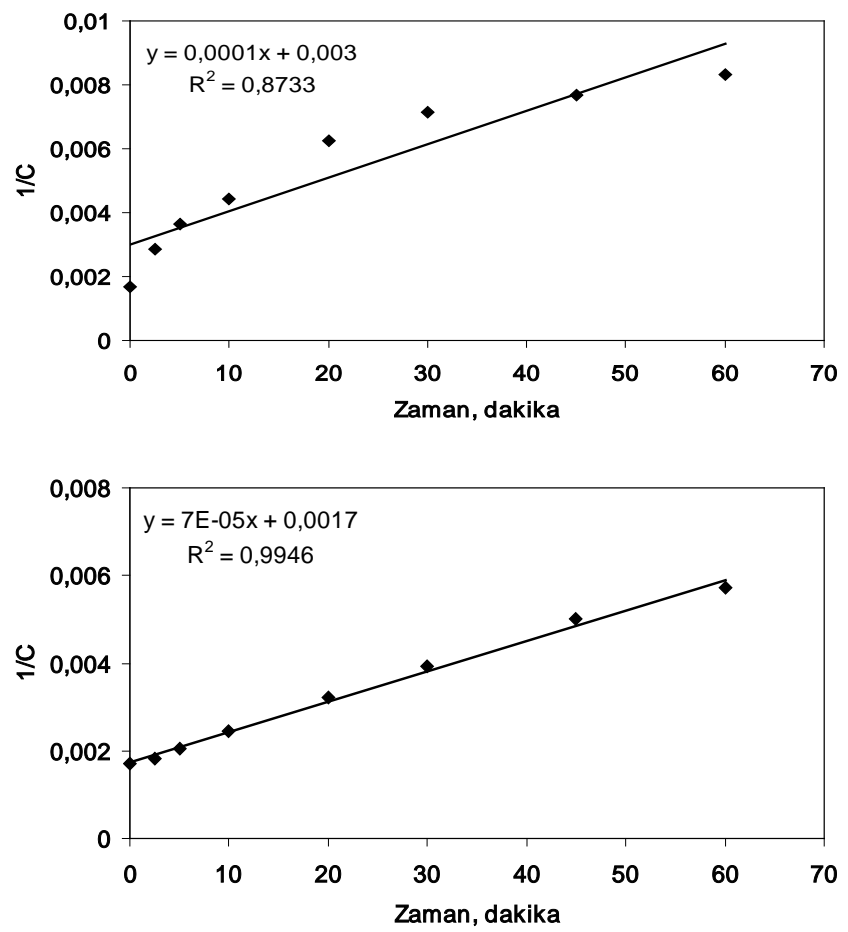

Şekil 5. Klasik (a) ve modifiye (b) Fenton prosesleri için ikinci dereceden kinetik grafikleri.

\section{Sonuç}

$\mathrm{Bu}$ çalışmada emaye kaplama tesisine ait endüstriyel atıksudan, klasik ve modifiye Fenton prosesleri ile KOİ giderimi kıyaslamalı olarak araştırılmıştır. Çalışma kapsamında Fenton prosesinin esas işletme parametreleri olan başlangıç pH'ı, katalist demir $\left(\mathrm{Fe}^{2+} / \mathrm{Fe}^{0}\right)$ ve $\mathrm{H}_{2} \mathrm{O}_{2}$ konsantrasyonlarının optimizasyonları ve kinetik incelemesi üzerinde durulmuştur. Deneysel çalışma sonucunda optimum şartlar, klasik Fenton prosesi için $\mathrm{pH}=3,\left[\mathrm{Fe}^{2+}\right]=150 \mathrm{mg} / \mathrm{L}$ ve $\left[\mathrm{H}_{2} \mathrm{O}_{2}\right]=250 \mathrm{mg} / \mathrm{L}$ ve modifiye Fenton prosesi için ise $\mathrm{pH}=3,\left[\mathrm{Fe}^{2+}\right]=200 \mathrm{mg} / \mathrm{L}$ ve $\left[\mathrm{H}_{2} \mathrm{O}_{2}\right]=200 \mathrm{mg} / \mathrm{L}$ olarak belirlenmiştir. Artan katalist demir konsantrasyonunun radikal süpürücü etkilerinden dolayı arıtma verimini düşürdüğü belirlenmiştir. $\mathrm{Bu}$ optimum şartlarda, emaye kaplama endüstrisi atıksuyunda klasik Fenton prosesi ile $\% 82$ ve modifiye Fenton prosesi ile \% 58 KOİ giderim verimi elde edilmiştir. Ayrıca KOİ gideriminin hızlı ve yavaş oksidasyon aşamaları olmak üzere iki aşamada gerçekleştiği belirlenmiştir. Deneysel verilerin kinetik incelenmesinde, KOİ gideriminin her iki proses için ikinci derece kinetiğe uyduğu tespit edilmiştir. Sonuç olarak, klasik Fenton prosesinin bu tür endüstriyel atıksuların fizikokimyasal arıtımı için verimli bir proses olduğu görülmüştür. 


\section{Kaynaklar}

[1] Özdemir, C., Karataş, M., Şahinkaya, S., Argun, M.E., "Physico-chemical studies of enamel cover industry wastewater”, Asian Journal of Chemistry, 21 (2), 964 - 970, 2009.

[2] Gogate, P.R., Pandit, A.B., "A review of imperative technologies for wastewater treatment. I: Oxidation technologies at ambient conditions”, Advances in Environmental Research, 8, 501551, 2004.

[3] Neyens, E., Baeyens, J., “A review of classic Fenton’s peroxidation as an advanced oxidation technique”, Journal of Hazardous Materials 98, 33 - 50, 2003.

[4] Ozdemir, C., Tezcan, H., Sahinkaya, S., Kalıpc1, E., "Pretreatment of olive oil mill wastewater by two different applications of Fenton oxidation processes”, Clean Soil Air Water, 38, 11521158, 2010.

[5] Guclu, D., Sirin, N., Sahinkaya, S., Sevimli, M.F., “Advanced treatment of coking wastewater by conventional and modified Fenton processes”, Environmental Progress and Sustainable Energy, 32, 176 - 180, 2013.

[6] Bremner, D. H., Burgess, A. E., Houllemare, D., Namkung, K. C., "Phenol degradation using hydroxyl radicals generated from zero-valent iron and hydrogen peroxide”, Applied Catalysis B: Environment, 63, 15-19, 2006.

[7] Arslan, I., Akmehmet Balcioglu, I., "Degradation of commercial reactive dyestuffs by heterogeneous and homogenous advanced oxidation processes: A comparative study, Dyes and Pigments, 43, 95-108, 1999.

[8] Azbar, N., Yonar, T., Kestioglu, K., “Comparison of various advanced oxidation processes and chemical treatment methods for COD and color removal from a polyester and acetate fiber dyeing effluent”, Chemosphere, 55, 35-43, 2004.

[9] Kiril Mert, B., Yonar, T., Yalili Kilic, M., Kestioglu, K., "Pre-treatment studies on olive oil mill effluent using physicochemical, Fenton and Fenton-like oxidations processes”, Journal of Hazardous Materials, 174, 122-128, 2010.

[10] APHA, American Public Health Association, Standard Methods for Examinations of Water and Wastewater, 21th ed., American Public Health Association/ American Water Works Association/Water Environment Federation, Washington DC, USA, 2005.

[11] Li, J.T., Song, Y.L., "Degradation of AR 97 Aqueous solution by combination of ultrasound and Fenton reagent”, Environmental Program and Sustainable Energy, 29, 101-106, 2009.

[12] Kiril Mert, B., Yonar, T., Yalili Kilic, M., Kestioglu, K., "Pre-treatment studies on olive oil mill effluent using physicochemical, Fenton and Fenton-like oxidations processes”, Journal of Hazardous Materials, 174, 122-128, 2010.

[13] Walling, C., “Fenton’s reagent revisited”, Accounts of Chemical Researchs, 8, 125-131, 1975.

[14] Bergendahl, J.A., Thies, T. P., “Fenton's oxidation of MTBE with zero valent iron”, Water Research, 38, 327-334, 2004.

[15] Kusic, H., Koprivanac, N., Srsan, L., “Azo dye degradation using Fenton type processes assisted by UV irradiation: A kinetic study”, Journal of Photochemistry and Photobiology A: Chemistry, 181, 195-202, 2006. 